73rd Conference of the Italian Thermal Machines Engineering Association (ATI 2018), 12-14 September 2018, Pisa, Italy

\title{
Performance of two different types of cathodes in microbial fuel cells for power generation from renewable sources
}

\author{
Mariagiovanna Minutillo ${ }^{\mathrm{a} *}$, Fabio Flagiello ${ }^{\mathrm{a}}$, Rosa Anna Nastro ${ }^{\mathrm{a}}$, Pasquale Di Trolio ${ }^{\mathrm{a}}$, \\ Elio Jannelli ${ }^{\mathrm{a}}$, Alessandra Perna ${ }^{\mathrm{b}}$ \\ ${ }^{a}$ University of Naples Parthenope, Department of Engineering, Naples, Italia \\ ${ }^{b}$ University of Cassino and Southern Lazio, Department of Civil and Mechanical Engineering, Cassino, Italia
}

\begin{abstract}
Microbial fuel cells (MFCs) technology represents a new approach to the sustainable electric power production, thanks to the advantages of its green features. The performance and the cost efficiency of a MFC are affected by several factors, such as the reactor architecture, the microbial microflora and the "costs per power" ratio of the electrodes. For example, cathodes powered by platinum as catalyzer are really efficient, but also expensive. In this study, two materials for cathode were examined: i) an economical biochar-based material (BC), ii) an activated carbon (AC) cathode with a nickel mesh current collector and a polytetrafluoroethylene (PTFE) binder to limit oxygen diffusion to the anodic compartment. The performances were evaluated in terms of power density and current density.
\end{abstract}

(C) 2018 The Authors. Published by Elsevier Ltd.

This is an open access article under the CC BY-NC-ND license (https://creativecommons.org/licenses/by-nc-nd/4.0/) Selection and peer-review under responsibility of the scientific committee of the 73rd Conference of the Italian Thermal Machines Engineering Association (ATI 2018).

Keywords: Microbial Fuel Cells; Biochar; power production performances; renewable sources

\footnotetext{
* Corresponding author. Tel.: +39-081-547-6792;

E-mail address: mariagiovanna.minutillo@uniparthenope.it
} 


\section{Introduction}

Microbial Fuel Cells (MFCs) are an emerging technology that combines biological catalytic redox activity with electrochemical reactions. A MFC is a device that uses bacteria to catalyze the conversion of organic matter into electric power [1]. Electrons and protons are produced in the anodic compartment as a consequence of biochemical processes mediated by microbial metabolism. While electrons are transferred from the anode to the cathode through an external circuit, protons derived diffuse through an electrolytical solution to the cathode, where electrons, protons and oxygen react to form simple water. Different substrates like acetate, glucose and organic urban waste can be oxidized by bacteria, producing electrons and protons at the anode [2]. Energy production from microbial activities is known since 1911, when Potter [3] started his first experiments with yeast extract and glucose, reaching a maximum voltage of $0.4 \mathrm{~V}$. Since then, a great improvement in MFC performance was achieved using different microbes and more complex electrodes, being able to reach up to $0.80 \mathrm{~V}$ [4] using activated carbon cathodes with platinum catalyzer and producing electric currents and power in the order of Ampere and Watt per square meter of cathodic surface [5]. Thanks to these results, the development of MFCs went through in an interesting stage, with some working products in the field of biosensors [6], mobile phone recharging [7], and LEDs lighting [8]. The ability of microorganisms to degrade biomasses producing meanwhile current, is a key value that highlights the importance of a continuous research on reactors shape, materials, microbial consortium and electrodes; it is important to know the actual results are reachable only using complex component configurations, so new frontiers of the MFCs research are focused in searching for cheaper ways to build reactors, pointing the attention on reusable compounds, biodegradable materials, 3D printing technology and more electroactive microbes consortium[9]. An interesting material for the development of electrodes is the biochar. Biochar is the result of vegetable organic material pyrolysis and, due to its nature very similar to the graphite one from a chemical and physical point of view, it is cheap and a biodegradable. In this work, we tested Biochar (BC) and Activated Carbon with a PTFE binder (AC) materials as cathodes in single-chamber, air-cathode cuboid MFCs (28 $\mathrm{ml}$ in volume). The AC/PTFE material was provided by VITO (Mol, Belgium). All MFCs had a carbon fiber brush as an anode and a saline solution containing sodium acetate $(1 \mathrm{~g} / \mathrm{L})$ as electrolyte [10]. Regarding to the inoculum, a 30-days-old biofilm was obtained from compost leachate by applying an external resistor (1000 $\Omega$ ) in a three electrodes system. Cyclic Voltammetry was also performed to evaluate the electrons exchange at the electrodes.

\section{Material and Methods}

\subsection{MFC description}

Two cubic "Lexan" made, air-cathode MFCs with a cylindrical chamber of $4 \mathrm{~cm}$ long and $7 \mathrm{~cm}^{2}$ cross section [11] were equipped with carbon fiber brushes anodes of $30 \mathrm{~cm}^{2}$ total area $(2.5 \mathrm{~cm}$ diameter and $2.5 \mathrm{~cm}$ length), bought from Millirose Company (Millirose, USA). The MFCs operated in a membraneless configuration with the anode fully submerged in saline solution made up of $0.82 \mathrm{~g}$ of sodium acetate, $\mathrm{PBS}$ containing $\mathrm{NH}_{4} \mathrm{Cl}(0.30 \mathrm{~g} / \mathrm{L})$, $\mathrm{NaH}_{2} \mathrm{PO}_{4} \mathrm{H} 2 \mathrm{O}(5 \mathrm{~g} / \mathrm{L}), \mathrm{Na} 2 \mathrm{HPO} 4 \mathrm{H} 2 \mathrm{O}$ (3 g / L), KCl (0.15 g / L), and vitamins solution (12.5 mL) [10]. The final volume of each cell was $28 \mathrm{ml}$. The anodes were incubated at $37^{\circ} \mathrm{C}$ for 7 days in a suspension made up by $50 \%$ compost and $50 \%$ saline solution, after that the anode was put in a three electrodes system fed with fresh compost suspension for further 30 days, with a $1000 \Omega$ external resistor connected to stimulate the genesis of an electroactive biofilm before being used for cathode materials testing. Compost was provided by an industrial waste treatment facility located in Caivano (Italy). Two different types of cathodes were used. The first one was the biochar (BC), a carbon-based material consisting of mineral phases, amorphous carbon, graphitic carbon and labile organic molecules. This material can be used in the steel industry as thermal insulation during the steel making processes. Figure 1a shows the MFC in which biochar is used as cathode (BC-MFC).

The second tested cathode was composed by an activated carbon (AC) layer, pressed on a polytetrafluoroethylene (PTFE) binder and surrounded by a Ni mesh current collector as described in Zhang et al. [5]. Figure 1b shows the MFC in which this cathode is used (AC/PTFE-MFC). 


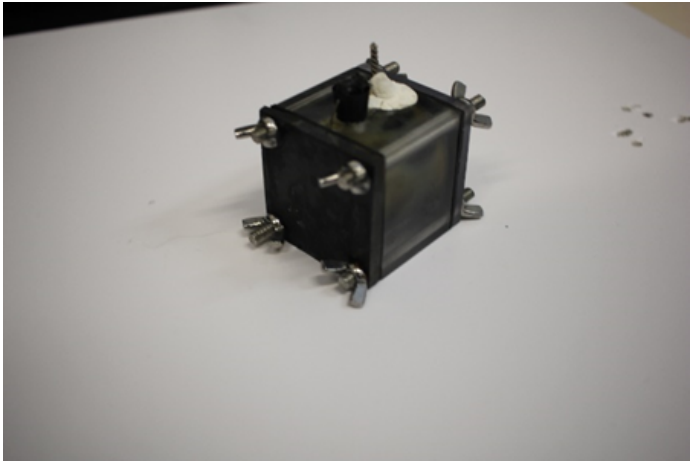

Fig.1a BC-MFC cathode on a cubic shape cell

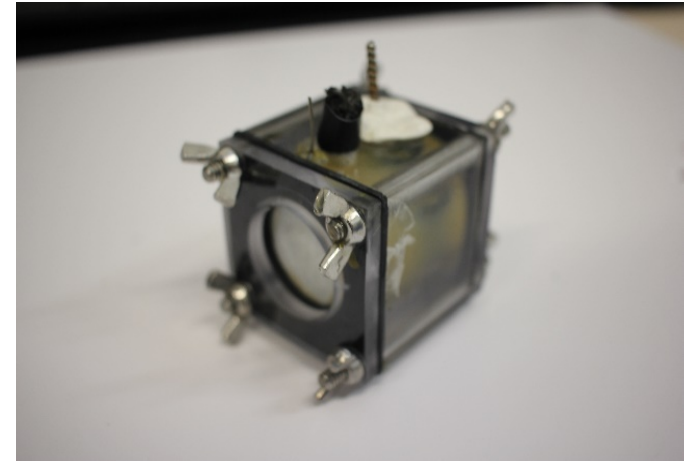

Fig.1b AC / PTFE cathode on a cubic shape cell

\subsection{Measurement techniques}

The chemical characteristics of AC/PTFE MFC are reported in the technical literature [5]. The biochar characteristics in terms of porosity were measured in our lab using the Matko' saturation methods [12]. This analysis allowed to estimate the porosity of $\mathrm{BC}$ cathode, that is equal to $5 \%$.

Moreover, in order to characterize the electrochemical behaviour of the tested electrodes, a Cyclic Voltammetry was conducted by using an AUTOLAB system model PGSTAT204 (Metrohm Autolab) with an Ag/AgCl as reference electrode $(+0,200 \mathrm{~V})$.

This last analysis allowed to evaluate the microbial redox activity of the MFCs. Cyclic voltammetry analysis (figures 2 and 3) were executed on the electrodes of both cells with a scan rate of $2.5 \mathrm{mV} / \mathrm{s}$. Regarding the BC cathode, the voltammetry range went from $0.9 \mathrm{~V}$ to $-1 \mathrm{~V}$, while $\mathrm{AC}$ cathode one went from $-0.80 \mathrm{~V}$ to $0.60 \mathrm{~V}$, the $\mathrm{AC}$ cathode didn't show redox peaks, while BC cathode showed a peak around $0.01 \mathrm{~V}$. Both cathodes showed a high overpotential that, in case of biochar could be ascribed to it thickness $(0.6 \mathrm{~cm})$.

Regarding the anodes, both CV shapes highlight the biofilm activity; it can be possible on both anodes to recognize a redox peak at $-0.04 \mathrm{~V}$ and $-0.86 \mathrm{~V}$, respectively equivalent to a Fe redox (figure 4).

The anode CV parameters were: Start potential at $-1 \mathrm{~V}$, Stop potential at $0.2 \mathrm{~V}$, scan rate of $2.5 \mathrm{mV} / \mathrm{s}$. The redox peaks absence and the simultaneous presence of power overshoot curves on the AC/PTFE cathode graphs show a working difficulty caused probably by biofilm cathodes growing.

The power overshoot is a "doubling back" effect of the voltage and power curves toward lower currents; when an electron depletion occurs, a power overshoot happens and MFC performances deteriorate after reaching the current peak.

Several causes can produce overshoots, such as the increase of internal resistance, limited organic substrate, high electron transfer resistance [13]. Otherwise it's really important to notice that BC cathode doesn't experience overshoots even with small resistors, so despite its poor performances, can better handle the electrochemical dynamics occurring in the MFC environment.

Polarization and power density curves were obtained using a data acquisition system (properly developed by the authors [14]) able to record the cell voltage (V) by applying customized external loads ranging from $17 \mathrm{k} \Omega$ to 100 $\Omega$.

Thus, by applying the known equations, the current data and the electric power were determined. These results were expressed in terms of current density and power density taking into account the cathode surface $\left(7 \mathrm{~cm}^{2}\right.$ of active area). 


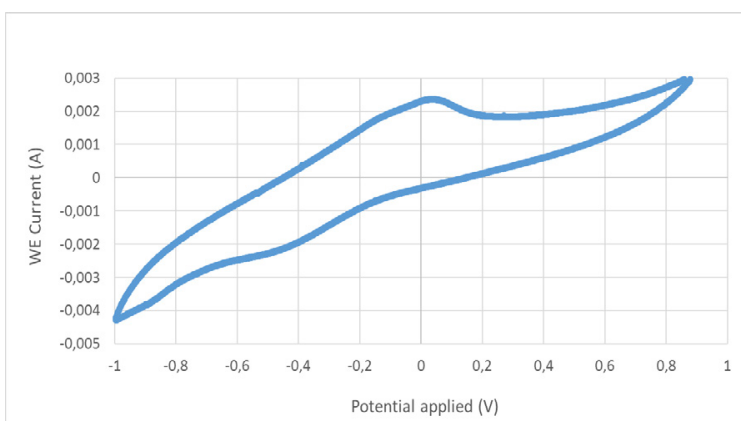

Fig.2 - Cyclic Voltammetry of BC cathode

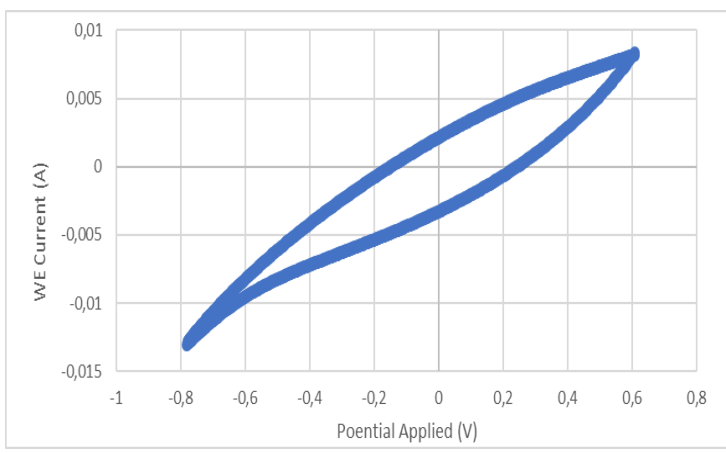

Fig.3 - Cyclic Voltammetry of AC/PTFE cathode

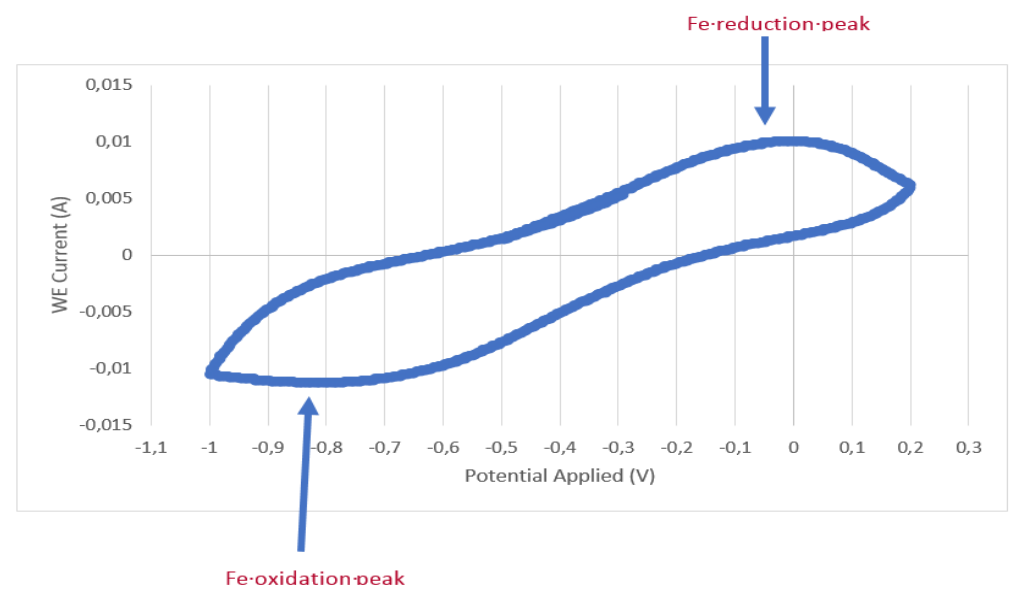

Fig. 4 - Anodes Cyclic Voltammetry details with Fe redox peak

\section{Results and Discussion}

\subsection{Performances comparison}

The experimental tests were carried out using the single cycle method [11]. the cells were connected to a resistors ladder (ranging from $17 \mathrm{k}$ to $100 \mathrm{ohm}$ ). The resistances were varied each $5 \mathrm{~min}$. The data were recorded each 30 second by the developed data acquisition System.

Data were recorded for 1 month; the $\mathrm{pH}$ of the cells were monitored during the tests and a $\mathrm{NaOH} 0.1 \mathrm{M}$ solution was added when needed in order to maintain $\mathrm{pH}$ at 7 . Figure 5 illustrates the power densities measured for the two tested cells (BC-MFC and AC/PTFE-MFC) during the experiments. The values refer to the mean power measured during each week.

As it can be noted, the AC/PTFE-MFC has higher performance during the time. The best performance $\left(241 \mathrm{~mW} / \mathrm{m}^{2}\right)$ is achieved at the third week. In both cells the performances decreased at the forth week. This behavior was, probably, due to the growth of a biofilm on the cathode that caused an increasing of the cell internal resistance. 
Figures 6 and 7 illustrate the comparison between the polarization curves and the power densities of the two tested cells measured at the third week, when the best performances were reached.

As it worth nothing that, the AC/PTFE-MFC has a voltage that ranges from $0.47 \mathrm{~V}$ (in OCV condition) to $0.34 \mathrm{~V}$ and the maximum power is $241 \mathrm{~mW} / \mathrm{m}^{2}$ at $702 \mathrm{~mA} / \mathrm{m}^{2}$ (the applied resistance is $700 \Omega$ ), while the BC-MFC has a voltage that ranges from $0.30 \mathrm{~V}$ (in OCV condition) to $0.16 \mathrm{~V}$ and the maximum power is $32 \mathrm{~mW} / \mathrm{m}^{2}$ at $196 \mathrm{~mA} / \mathrm{m}^{2}$ (the applied resistance is $1200 \Omega$ ).

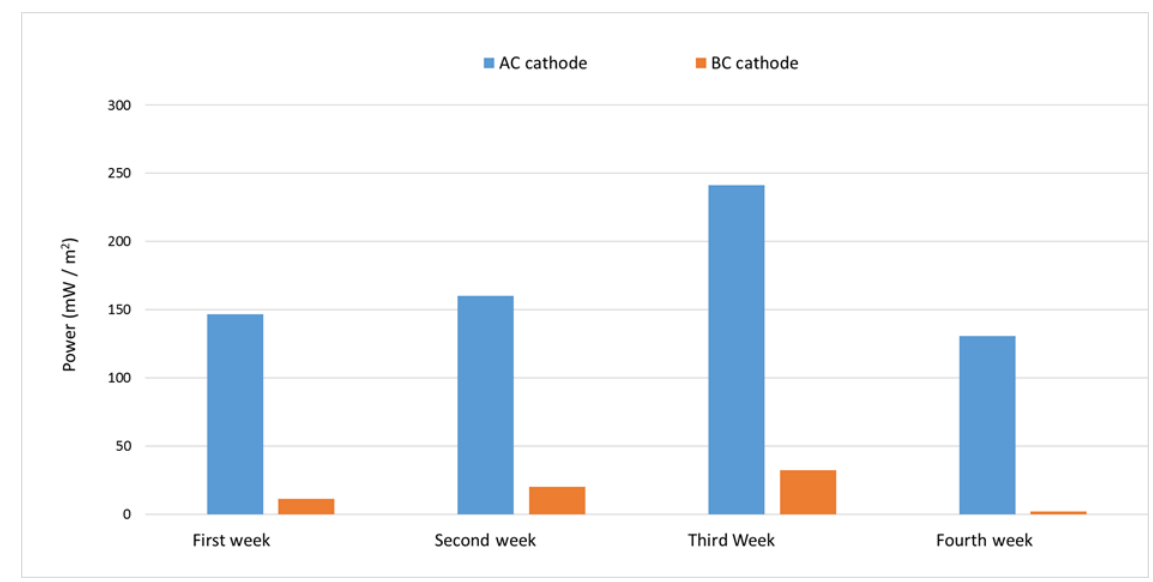

Fig. 5 AC vs BC histogram performances during the four

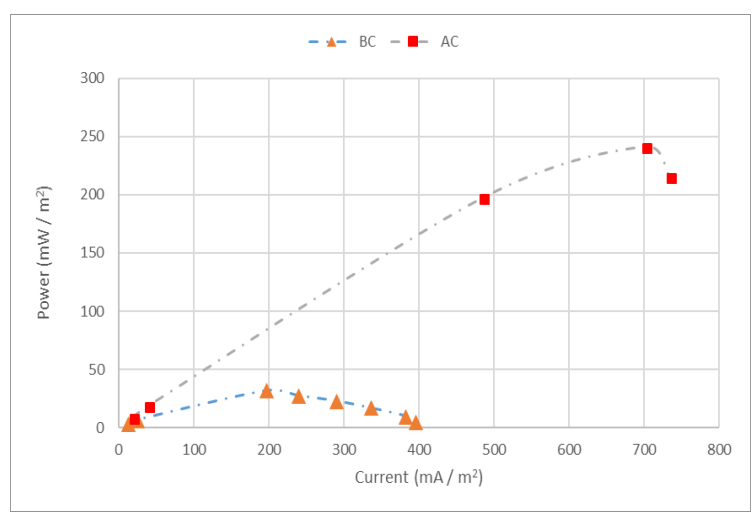

Fig. $6 \mathrm{AC}$ vs $\mathrm{BC}$ polarization curves

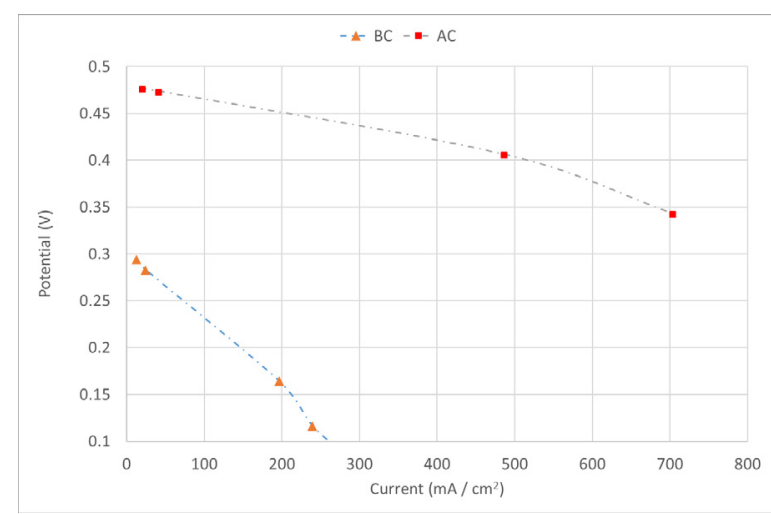

Fig. 7 AC vs BC power curves 


\section{Conclusion}

In this work the behavior and the performances of two cells that use different types of cathodes were investigated. The aim of this study was to evaluate the using of a cheap and eco-compatible electrode as a novel solution for the development of MFCs. The following cathodes were tested: i) an economical biochar-based material (BC), ii) an activated carbon (AC) cathode with a nickel mesh current collector and a polytetrafluoroethylene (PTFE) binder. Results show that the BC-MFC has lower performance (32 vs $241 \mathrm{~mW} / \mathrm{m}^{2}$ ) with respect to AC/PTFE-MFC. This gap is high and, even if BC is very cheap and can be considered a "green" material (it is a recycled material), it is needed to conduct further studies on its optimization for sustaining its utilization.

On the other hand, the AC/PTFE cathode, even if is commonly used since 2006 in lots of MFCs, has a complex composition and is not a material coming from a recycling circuit; moreover, the overshoot limitations shown by the $\mathrm{CV}$ analysis, impact on the overall performances.

\section{Acknowledgements}

Research supported by University of Naples "Parthenope" for the project "Microbial fuel cell as new technology for bioelectricity generation: Design and Development".

\section{References}

[1] Liu, H.; Logan, B. E. Electricity generation using an air-cathode single chamber microbial fuel cell in the presence and absence of a proton exchange membrane. Environ. Sci. Technol. 38 (2004): 4040-4046

[2] Nastro, R. A., et al. "Microbial fuel cells in solid waste valorization: trends and applications." Modelling Trends in Solid and Hazardous Waste Management. Springer, Singapore, (2017): 159-171.

[3] M.C. Potter Proc. R. Soc. B, 8 Electrical effects accompanying the decomposition of organic compounds 84 (1911): 260-276

[4] Logan, B.E., S. Cheng, V. Watson, and G. Estadt. Graphite Fiber Brush Anodes for Increased Power Production in Air-Cathode Microbial Fuel Cells. Environ. Sci. Technol., 41(9) (2007):3341-3346.

[5] Zhang, F., S. Cheng, D. Pant, G. Van Bogaert, and B.E. Logan.. Power generation using an activated carbon and metal mesh cathode in a microbial fuel cell. Electrochem. Commun. 11(11) (2009): 2177-2179.

[6] Yang, H., Zhou, M., Liu, M. et al. Biotechnol Lett 37 (2015):2357.

[7] Xavier Alexis Walter, Andrew Stinchcombe, John Greenman, Ioannis Ieropoulos, Urine transduction to usable energy: A modular MFC approach for smartphone and remote system charging, Applied Energy, 192 (2017): 575-581

[8] Iwona Gajda, John Greenman, Chris Melhuish, Ioannis Ieropoulos, Simultaneous electricity generation and microbially-assisted electrosynthesis in ceramic MFCs, Bioelectrochemistry, 104 (2015): 58-64

[9] Ronald Huarachi-Olivera, Alex Dueñas-Gonza, Ursulo Yapo-Pari, Patricia Vega, Margiht Romero-Ugarte, Juan Tapia, Luis Molina, Antonio Lazarte-Rivera, D.G. Pacheco-Salazar, Mario Esparza, Bioelectrogenesis with microbial fuel cells (MFCs) using the microalga Chlorella vulgaris and bacterial communities, Electronic Journal of Biotechnology, 31 (2018): 34-43

[10] Cheng, S., H. Liu and B.E. Logan.. Power Densities Using Different Cathode Catalysts (Pt and CoTMPP) and Polymer Binders (Nafion and PTFE) in Single Chamber Microbial Fuel Cells. Environ. Sci. Technol. 40(1) (2004):364-369

[11] Watson, V.J. and B.E. Logan.. Analysis of polarization methods for elimination of power overshoot in microbial fuel cells. Electrochem. Commun. 13(1) (2004):54-56.

[12] V. Matko. Porosity Determination by Using Stochastics Method. AUTOMATIKA 44(2003) 3-4, 155-162

[13] Kim, B., J. An, and I. S. Chang. "Elimination of Power Overshoot Caused by Electron Depletion of Limited Anodic Kinetic at Bio-anode through Assistance Current in Microbial Fuel Cell." ChemSusChem (2016)

[14] Nicole J, Nastro RA, Cigolotti V, Minutillo M, Falcucci G, Low pH, high salinity: Too much for microbial fuel cells?, Applied Energy, 192 (2017): 543-550 